\title{
Êxtases e martírios
}

\section{Paulo Eduardo Carvalho}

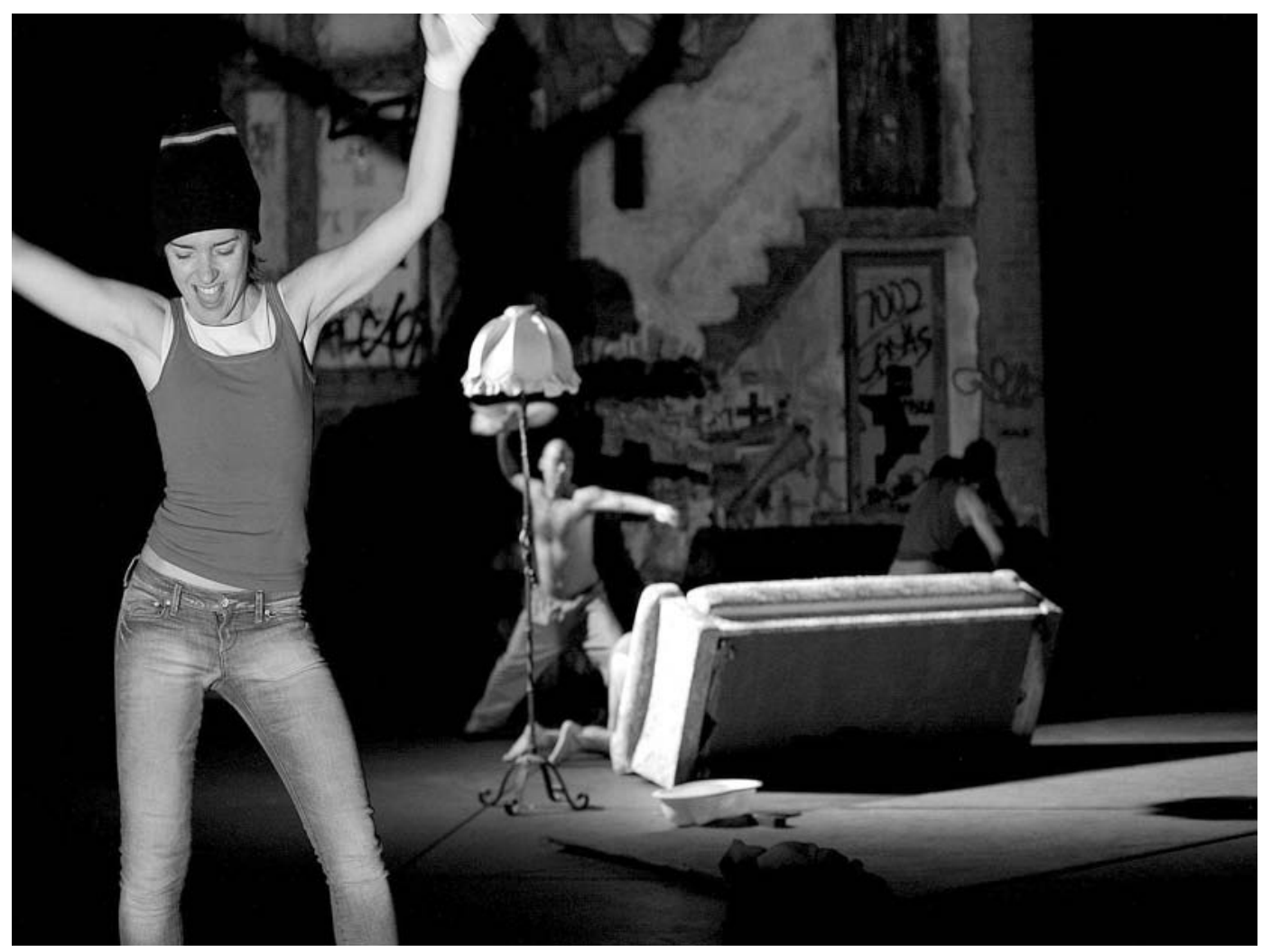

Titulo: Plasticina (Plastilin, 2000): Autor:Vassili Sigarev. Tradução: António Pescada. Encenação: Nuno Cardoso. Cenografia:F. Ribeiro. Figurinos: Migue Flor. Música: Sérgio Delgado. Desenho de luz: José Álvaro Correia. Movimento: Marta Silva. Preparação vocal: Inês Vicente. Graffiti: Miguel Januário. Interpretação:Alexandra Gabriel, Ana Brandão, Cátia Pinheiro, Daniel Pinto, Fernando Moreira, João Miguel Melo, Luis Araújo, Miguel Rosas, Patricia Brandão, Paulo Moura Lopes, Sandra Salomé e Tónan Quito. Produção: Teatro Nacional S. João. Local e data de estreia:Teatro Carlos Alberto, 16 de Março de 2006.

Titulo: Mãos mortas (Dead Hands, 2004). Autor: Howard Barker. Tradução: Pedro Cavaleiro. Encenação: Rogério de Carvalho. Assistência de encenação: Carla Miranda. Dramaturgia: Rogério de Carvalho e Carla Miranda. Desenho de luz: Jorge Ribeiro. Figurinos: Ana Luena. Maquilhagem: Patricia Lima. Sonoplastia: Luis Aly. Arranjo cenográfico e adereços: Cláudia Armanda. Interpretação: Maria do Céu Ribeiro, Miguel Eloy e Wagner Borges. Produção: As Boas Raparigas. Produção executiva: Carla Moreira. Local e data de estreia: Estúdio Zero, 4 de Abril de 2006.

Explorando as possibilidades abertas por estes "Passos em volta", recenseiam-se aqui dois espectáculos muito diversos, nas suas respectivas condições de produção e estratégias criativas, unidos simplesmente pela partilha de uma comum sedução pelos desafios cénicos lançados pela criação dramática contemporânea e pelo facto de terem sido ambos estreados na cidade do Porto.

Desde a sua saída do Visões Úteis, em 1997 - grupo que ajudara a fundar em 1994 -, Nuno Cardoso tem consistentemente dedicado muitos dos seus investimentos cénicos à encenação. Desse labor têm resultado espectáculos caracterizados por uma inequívoca imaginação cénica e um grande cuidado e apuro formal, de que são exemplo as três produções do Ao Cabo Teatro - Purificados (2002), de Sarah Kane, Valparaíso (2002), de Don DeLillo, e Parasitas (2003), de Marius von Mayenburg - e, nos últimos três anos, na condição privilegiada, mas também com maior responsabilidade, de quase "encenador associado residente" do TNSJ, a encenação de 0 despertar da Primavera (2004), de Franz Wedekind, Woyzeck (2005), de Georg Büchner, e agora deste Plasticina, de Vassili Sigarev. Este conjunto de escolhas parece configurar também a vontade de explorar um determinado tipo de repertório, entre momentos 
Plasticina

de Vassili Sigarev,

enc. Nuno Cardoso,

TNSJ, 2006

fot. João Tuna.

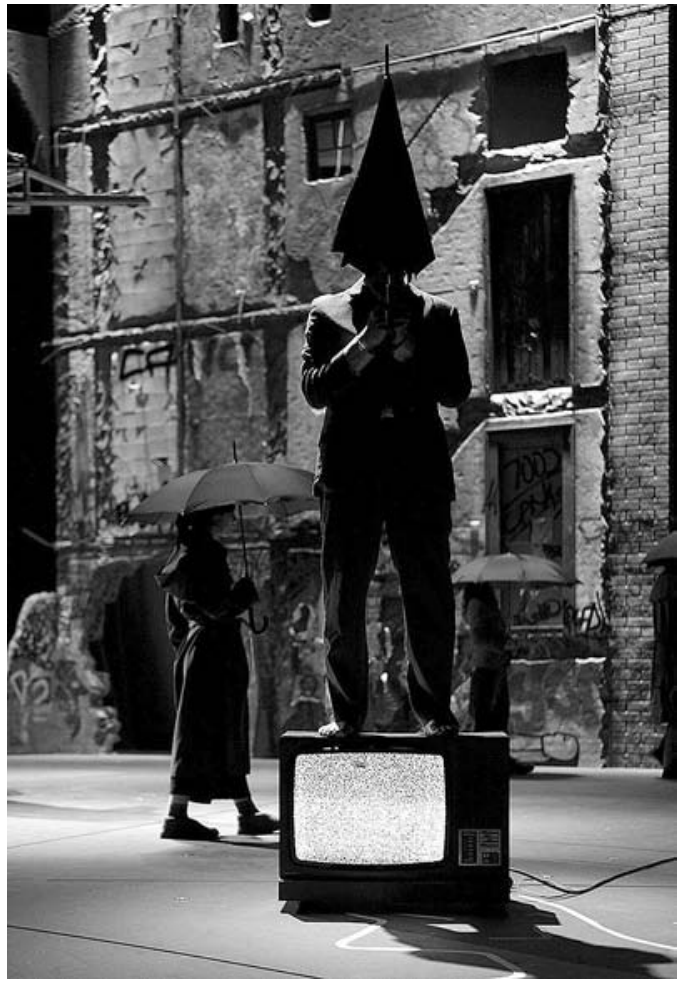

determinantes na emergência do "teatro moderno" e outros recentes desafios da dramaturgia contemporânea. A regularidade de alguns colaboradores - como Fernando Ribeiro na cenografia, José Álvaro Correia no desenho de luz, Sérgio Delgado na música, Teresa Azevedo Gomes ou Miguel Flor nos figurinos - e a insistência num núcleo comum de actores - de que podem ser exemplo Tónan Quito, João Miguel Melo, Cátia Pinheiro e alguns outros que integraram o seu mais recente espectáculo - justificam a sua afirmação de que: "Com Plasticina, procuro encerrar um trabalho de pesquisa iniciado em Purificados, de Sarah Kane" (Cardoso 2006: 11). Mas tal sugestão mais alargada de leitura, espontaneamente partilhada pelo espectador atento que tenha acompanhado toda aquela sequência de trabalhos, torna também mais complexa e exigente a recepção desta sua proposta cénica para o texto deste jovem dramaturgo russo (n. 1977), internacionalmente divulgado pelo Royal Court, com as produções de Plasticine, em 2002, Black Milk, em 2003, e Ladybird, em 2004.

Embora criado em paragens distantes, entre a Verkhniaia natal de Sigarev e Ekaterinburgo, onde o dramaturgo frequentou a Escola Superior de Teatro e onde reside actualmente, Plasticina apresenta um conjunto de características que tornam fácil a sua aproximação a alguma da dramaturgia britânica mais exportável da segunda metade dos anos noventa, definitivamente celebrizada por Aleks Sierz como o in-yer-face-theatre, devido à utilização de uma linguagem familiar e coloquial, dominada por um vocabulário obsceno, e ao favorecimento de ficções onde se cruzam a violência e o sexo, muitas vezes dominadas por algum tipo de desespero, que tanto pode resultar de uma projecção autobiográfica, como de uma intenção mais empenhada de crítica social. 0 texto de Sigarev acrescenta a tais dimensões um número abundante de personagens e de locais de acção, fazendo assentar a progressão da narrativa numa sucessão de cenas de duração muito variável, naquilo que Tania Moguilevskaia apresenta, no texto reproduzido no - mais uma vez, excelente Manual de Leitura do espectáculo - como uma "planificação cinematográfica do texto em sequências" (2006: 4). Como sugere ainda a mesma investigadora russa, "Plasticina narra a via-sacra de um adolescente órfão, que encaixa golpe atrás de golpe" (Ibidem: 7): o herói é o jovem Maksim, que experimenta uma sequência verdadeiramente martirizante de experiências de humilhação, ofensa e abuso, nos espaços sociais diversos da escola, da rua e do bairro, às mãos dos colegas e dos mais variados adultos, entre professores e outros anónimos.

Não obstante os imperativos narrativos - e trata-se aqui, inequivocamente, de contar uma "história" -, a peça mostra-se extraordinariamente aberta, devido não só à sua ostensiva fragmentação, mas também ao modo como parece mover-se hesitantemente entre algum recuperado naturalismo e alguma ambição poética, justamente, entre as limitações socialmente "sintomáticas" do in-yer-facetheatre e as suas pulsões mais metafísicas. Tal abertura cria desafios extraordinários a nivel da criação cénica, de que o encenador parece ter tido consciência: "há aqui uma liberdade imensa para inventarmos uma dramaturgia" (Cardoso 2006: 11). Nuno Cardoso confirma, neste

espectáculo, o seu talento na criação de quadros cénicos e na gestão quase coreográfica do movimento dos corpos em palco, com sugestivas consequências expressivas: a imagem recorrente das figuras de gabardina e chapéude-chuva ou a brilhante cena do grupo de casamento, numa sequência capaz de fazer lembrar o mais entusiasmante Kusturica, são disso bons exemplos. Como é também um bom exemplo o tratamento dado à figura espectral de Spira, o amigo morto de Maksim, numa bela composição de Miguel Rosas, tirando o melhor partido da grua que invade o espaço da cena.

Todo este registo, que poderiamos considerar mais devedor de algum expressionismo, não encontra, contudo, uma contrapartida equivalente noutros importantes 


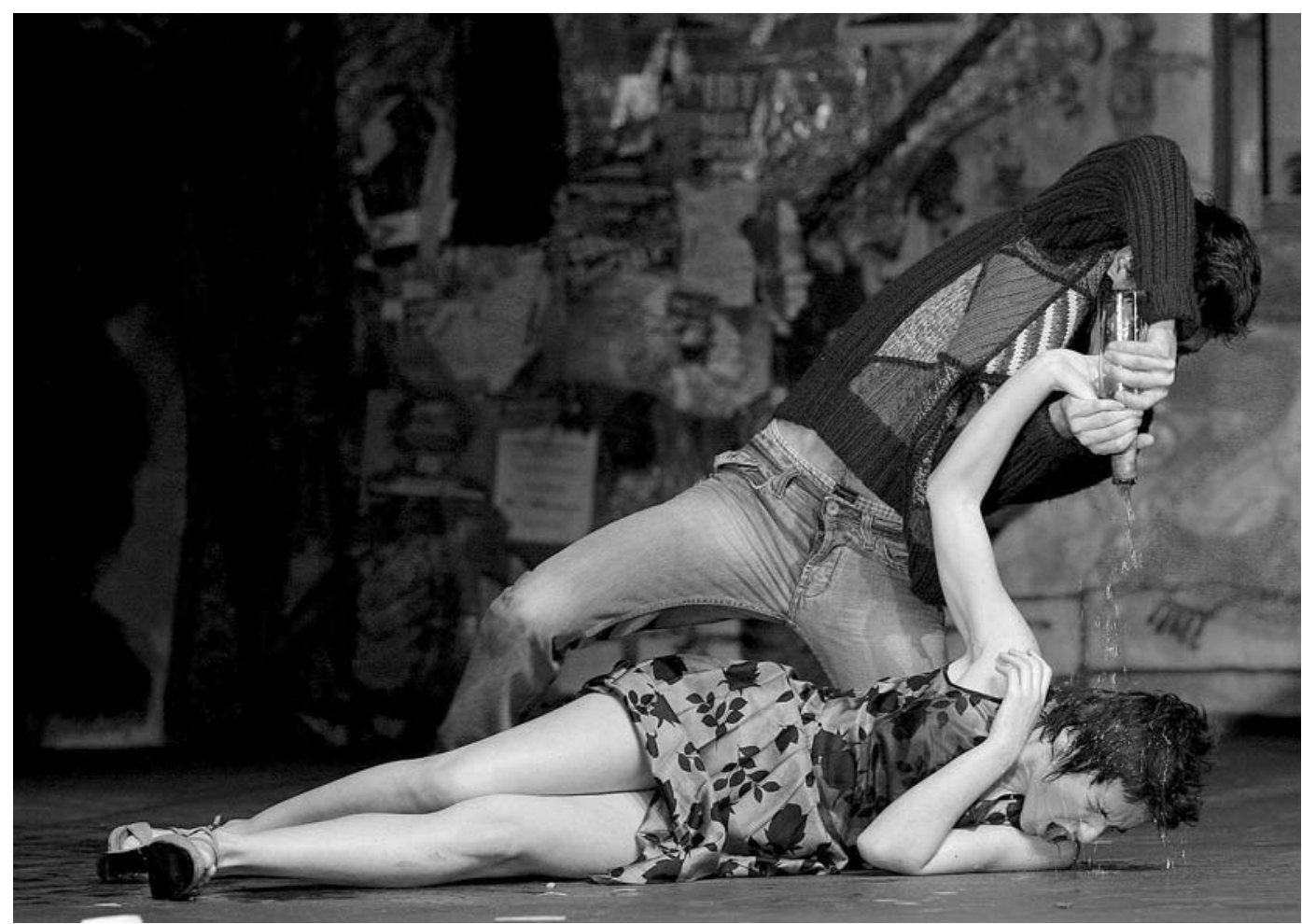

momentos do espectáculo, cuja resolução apresenta outro tipo de problemas. A opção assumida por um elenco dominantemente jovem cria dificuldades que nem a encenação nem a representação dos actores conseguiu resolver, reduzindo a caricaturas ou a figuras esvaziadas personagens tão determinantes como a professora que surpreende os miúdos na casa de banho, a avó de Maksim ou os dois adultos sádicos e violadores - em oposição, por exemplo, ao extraordinário, porque adequadamente histriónico, trabalho de Ana Brandão, no indefinido papel de "angariadora" de vítimas. Por aquilo que parece ser uma desatenção dramatúrgica ou um deficiente trabalho de pesquisa, perdem-se assim algumas dimensões indispensáveis de crueza e de afecto, decisivas para a expressão cénica do martírio do jovem Maksim. Além disso, a impositiva parede esventrada, criada por F. Ribeiro e "graffitada" por Miguel Januário, acabou por resultar excessivamente cenografada para ser capaz de assegurar, simultaneamente, o cenário de desolação onde progride o torturado herói e o seu próprio espaço mental.

No seu indiscutivel rigor de concepção, o espectáculo pareceu, assim, ressentir-se de uma limitada eficácia na gestão de atmosferas e situações tão diversas, com a intensidade que a ficção dramática, repetidamente, insistia em reclamar. Nada disto pôs em causa a qualidade do transfigurador trabalho do desenho de luz, das ousadas mas ajustadíssimas soluções encontradas pelos figurinos, nem do eclético ambiente musical, como não se duvidou do evidente empenho do conjunto de actores. Mas no fim de um ciclo, e quando o encenador confessa a vontade de abalançar-se aos universos de Shakespeare, Molière ou Tchekov, será de esperar um mais exigente rigor nos efeitos expressivos da cena, com destaque para um mais atento trabalho de representação, capaz de combinar um tão estimulante vitalismo com a mais consequente competência e codificação a que obriga todo o exercício de criação cénica.
Depois de Possibilidades, em 1998, e a reescrita radical de 0 tio Vânia, em 2000, As Boas Raparigas e Rogério de Carvalho regressaram, pela terceira vez, ao universo complexo de Howard Barker, com este mais recente Mãos mortas'. Aqueles dois espectáculos anteriores esclareciam já, de forma eloquente, a produtiva coincidência de alguns procedimentos artísticos entre o dramaturgo inglês e o encenador português, com destaque para um persistente trabalho sobre a voz e a palavra, como condutores de todo o restante trabalho cénico e de representação. Ambos os espectáculos se ressentiam, contudo, da sua natureza eminentemente formativa, ao insistirem na utilização de elencos muito jovens, com intérpretes recrutados nas escolas de teatro da cidade do Porto: para lá do expressivo virtuosismo então demonstrado por alguns desses intérpretes (caso, por exemplo, de Sérgio Praia, que se estreou em Possibilidades e assumiu o papel de Vânia na peça homónima), e dos fascinantes diagramas cénicos com que o encenador habitava o espaço, ambas as propostas apresentavam algumas dificuldades em se libertarem da sua condição de "exercício". Algo de simultaneamente exaltante e limitado volta a acontecer neste Mãos mortas.

Depois das suas colaborações com o Royal Court Theatre, a Royal Shakespeare Company, o Festival de Edimburgo ou a Joint Stock Theatre Company, durante toda a década de 70 e a primeira metade da década de 80, Howard Barker - cuja prolixidade criativa surge exemplarmente ilustrada num corpus dramático que conta já cerca de 50 peças - afasta-se, ou sente-se afastado, cada vez mais para as margens do sistema teatral britânico, o que explica a formação, em 1988, de The Wrestling School, uma companhia inicialmente constituida por actores saídos de outras estruturas. É no seio desse projecto mais "marginal" que Barker encontra aquilo que encara como as condições adequadas à prossecução do seu particular projecto cénico, que passa não só pela escrita
1 A estreia de Barker nos palcos portugueses data de 1997, com Cenas de uma execução, com tradução de Maria Teresa Cruz e encenação de Alberto Lopes e São José Lapa, no Teatro Nacional D. Maria II. Depois daquele espectáculo, a presença do dramaturgo entre nós ficou limitada à cidade do Porto, com a produção, para além dos dois espectáculos de As Boas Raparigas já referidos, de Judith, em 2000, e de Rostos em ferida, em 2001, pela extinta companhia MetaMortemFase, com tradução de Isabel Alves e encenação, respectivamente, de João Paulo Costa e Rogério de Carvalho. 
Mãos mortas,

de Howard Barker,

enc. Rogério de Carvalho,

As Boas Raparigas, 2006

(Miguel Éloy,

Maria do Céu Ribeiro

e Wagner Borges)

fot. Paulo Pimenta.

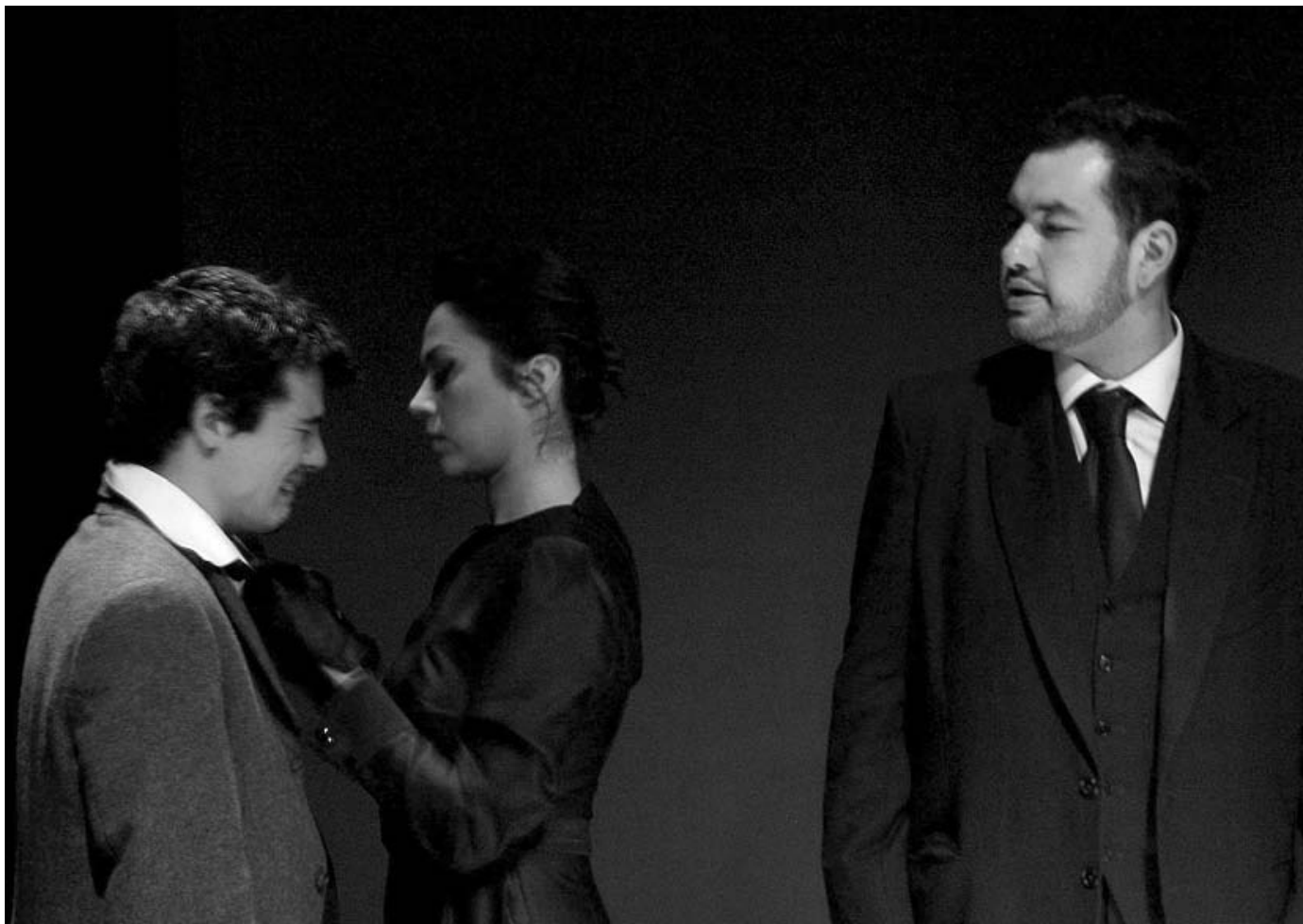

solitária de textos de teatro, mas também pela assunção da encenação e, muitas vezes, pela da cenografia dos espectáculos. Contemporânea da criação daquela companhia é a publicação da sua primeira recolha de escritos teóricos, Arguments for a Theatre, onde mais desenvolvidamente, mas sempre de um modo aforístico e epigramático, desenvolve a sua teoria - que não era mais do que a sistematização do trabalho criativo até então desenvolvido - do "teatro da catástrofe". (Mais recentemente, Barker publicou uma nova recolha de reflexões teóricas: Death, the One and the Art of Theatre.) Tal como o dramaturgo teve a oportunidade de esclarecer na conversa pública promovida pela companhia no dia 5 de Março, no espaço do Estúdio Zero², o seu é um teatro que se opõe ao "teatro humanista" da mensagem (ou da "massagem", como gosta de acrescentar), recusando a mais imediata transitividade praticada pela dramaturgia empenhada na denúncia social, avesso, por isso, a quaisquer pressupostos naturalistas e deliberadamente apostado na recuperação de um sentido quase arcaico do trágico e do poético: trata-se de um teatro das emoções,

orgulhosamente "artístico", assente no conflito, na dor e no êxtase da tragédia, intensificando as suas primitivas possibilidades instituais e irracionais.

Há em todo este projecto singular a busca de algo que se quer quase anárquico e bárbaro, numa espécie de

Em "Howard Barker, um sem-abrigo no teatro

britânico", publicado nas páginas do jornal Público, de 7 de Abril de 2006 (p.

35), Inês Nadais deu resumidamente conta do

conteúdo das

intervenções do

dramaturgo naquele

encontro. recuo a uma identidade pré-moral, e que é paralelo ao

culto de uma linguagem - e este é um teatro

eminentemente de linguagem - deliberadamente afastada do discurso quotidiano (e de quaisquer tentações

naturalistas), e ambiciosamente poética, fazendo coabitar o baixo e o elevado, o rude e o belo. Barker é um dos raros poetas da cena contemporânea, capaz de articular surpreendentemente o terror e a beleza, a ansiedade e o arrebatamento, com a ambição de fazer emergir novas percepções. Tal consciência programática, a já referida prolixidade e um certo isolamento criativo explicam o inevitável, mas contraditório, amaneiramento de algumas soluções retóricas características da sua dramaturgia, sem que tal, contudo, consiga inibir o fascínio que continua a ser ouvir e ver em cena um texto de Howard Barker, de tal modo extraordinária é a imagética convocada, tanto aquela estritamente verbal, como aquela imaginada para a figuração cénica.

Como já atrás se sugeriu, muitos dos procedimentos cénicos de Rogério de Carvalho mostram uma coincidência extraordinariamente produtiva com este universo teatral, facto que, mais uma vez, se reflectiu neste espectáculo. Mãos mortas ficará como uma notável criação cénica tanto a nivel do trabalho desenvolvido com a incorporação e elocução do texto pelos intérpretes, como a nivel do austero rigor com que todos os sinais cénicos são convocados, agilizados e postos em relação. Tratava-se, para esta peça de câmara, de dar corpo e voz a um estranho e oscilante triângulo, de ostensivos contornos eróticos, entre dois irmãos, que acorrem à casa paterna para uma espécie de velório do pai recentemente falecido, e a amante desse homem, cujo corpo morto é a única figuração permanente em cena. A Sopron de Maria do Céu Ribeiro terá sido uma das mais belas e inesqueciveis criações da actriz, que conseguiu juntar ao seu extraordinário poder elocutório a maturidade e a audácia interpretativas necessárias para acompanhar as violentas oscilações de registo sugeridas pelo dramaturgo. Os outros dois intérpretes - dois jovens actores da escola Superior de Teatro e Cinema de Lisboa -, embora desajustadamente jovens para a turbulenta espessura dos papéis em causa (Eff e Istvan), conseguiram impor-se pela competência do trabalho desenvolvido, com destaque para Wagner Borges que emprestou à sua personagem uma dimensão surpreendente de controlado delírio, deixando que a sua voz poderosa acabasse por funcionar como agente contaminador de um corpo relutante. Um poderoso minimalismo musical e um desenho de luz de raros efeitos 

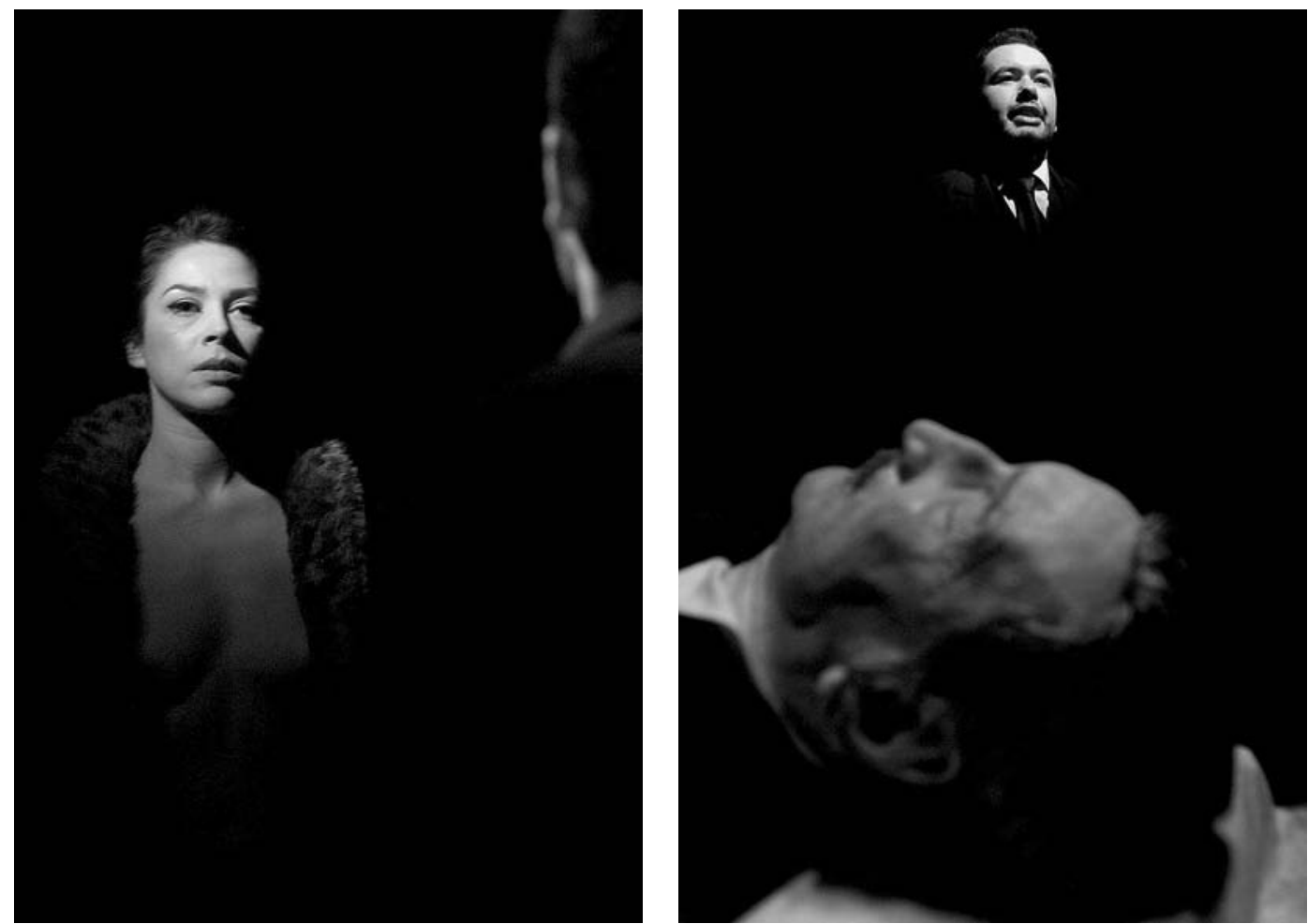

Mãos mortas,

de Howard Barker

enc. Rogério de Carvalho,

As Boas Raparigas, 2006 (Wagner Borges), fot. Paulo Pimenta.
Mãos mortas, de Howard Barker, enc. Rogério de Carvalho, Boas Raparigas, 2006 fot. Paulo Pimenta. expressionistas - alternadamente capaz de, através da quase obscuridade, proporcionar o necessário efeito hipnótico e de, optando por um agressivo cruzamento de raios de luz, sinalizar a explosão emotiva - surgiam só limitados por um "arranjo cenográfico" que teria merecido um tratamento mais cuidado, para uma mais conseguida sugestão da interioridade doméstica reclamada pela ficção dramática. Exactamente o tipo de cuidado demonstrado na figuração do corpo das personagens, a nível dos figurinos e da maquilhagem, com destaque, novamente para a figura de Sopron. 0 que, contudo, singularizou este trabalho foi a imensa consequência expressiva de um trabalho em profundidade sobre uma paleta árdua de registos interpretativos, capazes de dar forma à visionária ambição do dramaturgo de povoar a cena das suas ficções com verdadeiros corpos poéticos.

0 destaque final vai para o que pareceu, em ambos os espectáculos, um cuidado trabalho de reescrita em português dos textos de Vassili Sigarev e Howard Barker, respectivamente traduzidos por António Pescada e Pedro Cavaleiro. No primeiro caso, tornou-se notório o esforço pela recuperação de uma linguagem crua e despojada. No segundo, resultou particularmente eficaz a resistência a qualquer tentação normalizadora da complexa sintaxe do dramaturgo inglês, indispensável para o efeito encantatório e asfixiante da sua retórica.

\section{Referências bibliográficas}

BARKER, Howard (1993), Arguments for a Theatre [1989], Manchester, Manchester University Press.

- - (2004), Death, the One and the Art of Theatre, London \& New York, Routledge.

CARDOSO, Nuno / VAZ, João Pedro (2006), "Lado B", in Manual de Leitura de Plasticina, Porto, TNSJ, pp. 11-15.

MOGUILEVSKAIA, Tania (2006), "Vassili Sigarev e o novo teatro russo", trad. Regina Guimarães, in Manual de Leitura de Plasticina, Porto, TNSJ, pp. 4-6.

SIERZ, Aleks (2001), In-Yer-Face Theatre: British Drama Today, London, Faberand Faber. 